\title{
An Optimized Artificial Neural Network Model using Genetic Algorithm for Prediction of Traffic Emission Concentrations
}

\author{
Akibu Mahmoud Abdullah ${ }^{1}$, Raja Sher Afgun Usmani ${ }^{2}$, \\ Thulasyammal Ramiah Pillai ${ }^{3}$, Mohsen Marjani ${ }^{4}$ \\ School of Computer Science and Engineering, \\ Taylor's University, \\ Selangor, Malaysia
}

\author{
Ibrahim Abaker Targio Hashem ${ }^{5}$ \\ College of Computing and Informatics, \\ Department of Computer Science, \\ University of Sharjah, \\ 27272 Sharjah, UAE
}

\begin{abstract}
Global warming and climate change have become universal issues recently. One of the leading sources of climate change is automobiles. Automobiles are the prime source of air pollution in urban areas globally. This has resulted in a problematic and chaotic state in the development of an automatic traffic management system for capturing and monitoring vehicles' hourly and daily passage. With the significant advancement of sensor technology, atmospheric information such as air pollution, meteorological, and motor vehicle data can be harvested and stored in databases. However, due to the complexity and non-linear associations between air quality, meteorological, and traffic variables, it is difficult for the traditional statistical and mathematical models to analyze them. Recently, machine learning algorithms in the field of traffic emissions prediction have become a popular tool. Meteorological and traffic variables influence the variation and the trend of the traffic pollutants. In this paper, an optimized artificial neural network (OANN) was developed to enhance the existing artificial neural network (ANN) model by updating the initial weights in the network using a Genetic Algorithm (GA). The OANN model was implemented to predict the concentration of $\mathrm{CO}, \mathrm{NO}, \mathrm{NO}_{2}$, and $\mathrm{NO}_{x}$ pollutants produced by motor vehicles in Kuala Lumpur, Malaysia. OANN was compared with Artificial Neural Network (ANN), Random Forest (RF), and Decision Tree (DT) models. The results show that the developed OANN model performed better than the ANN, RF, and DT models with the lowest MSE values of 0.0247 for $C O, \mathbf{0 . 0 3 6 5}$ for $N O, \mathbf{0 . 0 5 4 2} N O_{2}$, and 0.1128 for $N O_{x}$. It can be concluded that the developed OANN model is a better choice in predicting traffic emission concentrations. The developed OANN model can help environmental agencies monitor traffic-related air pollution levels efficiently and take necessary measures to ensure the effectiveness of traffic management policy. The OANN model can also help decision-makers mitigate traffic emissions to protect citizens living in the neighborhood of highways.
\end{abstract}

Keywords-Optimized Artificial Neural Network (OANN); Genetic Algorithm; traffic emissions

\section{INTRODUCTION}

Global warming and climate change have become universal issues recently $[1,2]$. One of the leading sources of climate change is emissions from motor vehicles. Carbon monoxide $(\mathrm{CO})$, nitrogen dioxide $\left(\mathrm{NO}_{2}\right)$, carbon dioxide $\left(\mathrm{CO}_{2}\right)$, and nitrogen monoxide $(N O)$ are among the significant risk to human health and the environment, which can be emitted by motorized vehicles [3]. Road transport emissions exposure can increase the risk of lung cancer [4], respiratory and cardiovascular effects [5, 6], pulmonary, chronic diseases [7] and mortality [8, 9]. In 2015 air pollution, in general, are responsible for over 6 million deaths in the world $[10,11]$. There is more than 400,000 premature death in Europe [12], and around 7 million worldwide [13].

Automobiles are the prime sources of air pollution in city areas universally. For example, $80.49 \%$ of emissions in Beijing, China, were produced by motor vehicles [14]. It was also found that $80 \%$ of air pollution in the Lima Metropolitan Area was produced from automobiles [13]. in China, 85\% of emissions were from transport [15], while in the United Kingdom was $92 \%$ [16], and $75 \%$ in Malaysia [17], but in the United States, automobiles are responsible for emitting $57 \%$ of air pollution [7]. Many other studies also show that $92 \%$ of $C O$ and $65 \%$ of hydrocarbon $(H C)$ pollutants were emitted from the transportation activities in Shanghai [18], and $60 \%$ of $N O_{x}$ and $P M$ emissions were from heavy-duty trucks in China [19].

The variation and trend of air pollution strongly depend on meteorological parameters and traffic characteristics [20]. A study conducted in Shiraz, Iran, confirmed that meteorological conditions increase the air pollution level [21]; a similar result was also found in Karaj, Iran [22]. A relationship between air pollution and meteorological condition was studied in Beijing and Nanjing, China. The study reveals that air pollution concentrations depend on meteorological factors [23]. Research in Linfen city, China, shows negative correlations between air pollutants and meteorological parameters [24]. A study was conducted in Penang, Malaysia, to investigate the sources contributing to air pollution concentrations. Five air pollutants were investigated. The result shows that a negative correlation was found between relative humidity with $\mathrm{CO}, \mathrm{O}_{3}, \mathrm{SO}_{2}$, $P M_{10}$, and $\mathrm{NO}_{2}$.

A negative correlation was found between wind speed and $\mathrm{CO}, \mathrm{SO}_{2}$, and $\mathrm{NO}_{2}$, but positive relation with $P M_{10}$ and $\mathrm{O}_{3}$. Whenever temperature increases, the $\mathrm{O}_{3}, \mathrm{NO}_{2}, \mathrm{CO}$, and $P M_{10}$ pollutants increase too, but $\mathrm{SO}_{2}$ decrease [25]. A study on $\mathrm{O}_{3}$ variability due to meteorological parameters was investigated in Selangor, Malaysia. The result shows that wind speed, temperature, relative humidity, and wind direction significantly impact $O_{3}$ concentrations [26]. [27] 
studied air pollution variation due to meteorological in four areas in Malaysia, namely, Petaling Jaya, Cheras, Shah Alam, and Klang. The result reveals that meteorological parameters influenced the seasonal trend of air pollution. Association between air pollution and traffic characteristics has also been investigated. A study was conducted to compare the impact of traffic volume on air pollution levels during COVID-19 in Italy. Data from 2017 to 2018 before COVID-19 and 2020 data during COVID-19 were used. The result reveals that traffic volume significantly impacts $\mathrm{PM}_{10}, \mathrm{NO}_{x}, \mathrm{NO}$, and $\mathrm{NO}_{2}$ concentrations [28].

A study of [29] investigates the exposure of air pollution produced by vehicles on cyclists in Brazil. The research indicates an increase in motor vehicles during peak hours in the morning and evening. The expansion of the vehicle increases the level of air pollution. In addition, air pollution level due to traffic characteristics was studied in Japan [20]. The result indicates that the low speed of the vehicle increases the pollution level. Similarly, traffic volume and congestion increase the emission of air pollution in Kyoto, Japan. It was also found that trucks are the main contributor of $P M$ and $N O_{x}$ emissions. Furthermore, a study in Kuala Lumpur was conducted to investigate the effect of traffic characteristics on the air pollution level. The study reveals that air pollution level strongly depends on fuel consumption, traffic volume, vehicle speed, and waiting time on the road. The result also shows that lower traffic congestion reduces the level of air pollution in Kuala Lumpur [30].

With the rapid advancement of sensor technology, atmospheric information such as air pollution, meteorology, and motor vehicle data can be collected and stored in databases. Due to the complexity and non-linear associations that exist between air quality, meteorological, and traffic variables, it is difficult for traditional statistical and mathematical models to analyze them [31, 32]. Lately, the usage of machine learning algorithms such as long short term memory, random forest, support vector machine, decision tree, and artificial neural network (ANN) in traffic-related air pollution prediction has become popular [33]. ANN model appeared to be the most used model for predicting traffic emissions because it reduces time, cost, and complexity. It also provides fast and accurate prediction with less error and provides prediction values closer to the observed values [34]. ANN can solve complex multidimensional variables and non-linear problems related to traffic emission concentrations due to meteorological conditions and traffic features [34, 35].

In this paper, an optimized artificial neural network (OANN) was developed to enhance the existing artificial neural network (ANN) model by updating the weights in the network using a Genetic Algorithm (GA). The OANN model was implemented to predict the concentration of $\mathrm{CO}, \mathrm{NO}, \mathrm{NO}_{2}$, and $N O_{x}$ pollutants produced by motor vehicles in Kuala Lumpur, Malaysia. The remaining structure of the paper is given as follows. Section II discusses the related work on vehicle emissions prediction using the ANN model. Section III presents the methodology used in this study. Section IV presents the result and the comparison with existing machine learning models for evaluation. Finally, the conclusion is discussed in Section V.

\section{RELATED WORK}

Motor vehicles are producing harmful pollutants that disperse to the atmosphere [33]. These pollutants have significant impact on human health [36]. Several statistical models have been developed for predicting the traffic emissions concentrations at intersection, canyon, street, near the school, and many other locations. However, these statistical models could not predict the emissions rate due to the variability and influence of meteorological variables and traffic parameters [31]. Machine learning models have recently been applied. These models were able to predict the concentrations of emitted pollutants from motor vehicles. ANN has become the most popular model for predicting traffic-related air pollution [34]. These models are highly dependent on the independent variables provided in the study. There is a lack of either meteorological data or traffic data in many studies [37]. Several studies suggested that meteorological and traffic variable influence the trend and variation of traffic pollutants [33], such as relative humidity, temperature, wind direction, and wind speed, [38], traffic volume, vehicle speed [39], types of the vehicle, etc. [40].

The variables mentioned above are needed to predict emission levels. Still, it is not always available [37], for example, prediction of carbon monoxide $(C O)$ concentrations at Jiyin Ave and Shuanglong intersections was conducted by [41] using Gated Recurrent Unit (GRU) neural networks based in the absence of a meteorological dataset. The accuracy of the model's performance was found good with a root mean squared error (RMSE) of 0.088 and mean absolute error (MAE) of 0.056 . [42] proposed machine learning algorithms by comparing and selecting the best model with good performance to reduce the effect of Greenhouse gas (GHG) emitted by passenger vehicles on climate change in Canada. Artificial Neural Network (ANN) shows better performance over the other machine learning algorithms with RMSE of 0.442 and MAE of 0.347 . This study also lacks the meteorological dataset. ANN was developed by [43] to predict the emission of $\mathrm{CO}, \mathrm{CO}_{2}, \mathrm{NO}_{x}$, and $\mathrm{HC}$ from a liquefied natural gas bus in Zhenjiang, China, without considering meteorological features. The performance of the prediction of $\mathrm{CO}_{2}$ was unsatisfactory. The MSE value is 52, but the remaining predictions of the contaminants were good. The MSE value for $C O$ 2.23, $H C$ 0.68, and $N O_{x}$ 9.4. Carbon monoxide was predicted using a Non-linear Autoregressive Exogenous (NARX) based neural network in the absence of traffic data at Shiraz, Iran [44]. The proposed model performed well compared to the previous models with RMSE values of 0.43, R2 0.31, and MAPE 51.

There are some studies used three datasets, namely, air quality, meteorological, and traffic datasets. ANN was applied to predict the level of $\mathrm{NO}, \mathrm{NO}_{2}, \mathrm{O}_{3}, \mathrm{NO}_{x}, \mathrm{CO}_{2}, \mathrm{PN}_{10}$, $\mathrm{NH}_{3}, P M_{10}, P M_{2.5}$, and $P M_{1}$ pollutants from on-road vehicles at the street canyon in Germany. The model have the lowest RMSE for some pollutants, while others have the highest RMSE, which shows that the model has to be improved for predicting these pollutants. The RMSE for $\mathrm{NO}, \mathrm{NO}_{2}$, $\mathrm{O}_{3}, \mathrm{NO}_{x}, \mathrm{CO}_{2}, P \mathrm{~N}_{10}, \mathrm{NH}_{3}, P M_{10}, P M_{2.5}$, and $P M_{1}$ were $16.017,5.092,5.774,32.820,0.790,12,872.74,13.474$, $0.050,0.013$, and 0.010 [45]. [46] proposed an ANN model to predict $C O$ concentration at Subang Jaya Toll plaza, Selangor, Malaysia. Traffic and meteorological variables were used as an input to the model. The model shows good accuracy with 
MAE 0.8925, RMSE 1.2736, RAE 21.99, and RRSE 19.40. A comparison with ANN and developed ResNetELF was conducted [47] to predict the $\mathrm{CO}, \mathrm{CO}_{2}, \mathrm{NO}_{x}$, and $\mathrm{HC}$ levels. The ANN performed well with RMSE 0.0930 for $C O, 0.080$ for $\mathrm{CO}_{2}, 0.0856$ for $\mathrm{NO}_{x}$, and 0.0798 for $\mathrm{HC}$. Furthermore, [48] predict $\mathrm{NO}, \mathrm{CO}$, and $\mathrm{HC}$ concentrations using the ANN model. The model's performance was found good with RMSE 1.89, 0.97, 1.09 for $\mathrm{NO}, \mathrm{CO}$, and $\mathrm{CO}_{2}$. Table I presents the variables and size of the dataset used by previous studies. Table II summarizes the performance of the models used in the previous researches.

TABLE I. SUMMARY OF THE VARIABLES AND DATASET SIZE USED BY Previous STUdies

\begin{tabular}{|c|c|c|}
\hline Author & Variables & Dataset \\
\hline $\begin{array}{l}\text { (Wang et } \\
\text { al., 2020) }\end{array}$ & $\begin{array}{l}C O \text {, traffic volume, } \\
\text { population density. }\end{array}$ & $\begin{array}{l}\text { One } \\
\text { week }\end{array}$ \\
\hline $\begin{array}{l}\text { (Khan et } \\
\text { al., 2019) }\end{array}$ & $\begin{array}{l}C O \text {, car, truck, population, } \\
\text { year, and GDP transportation. }\end{array}$ & N/A \\
\hline $\begin{array}{l}\text { (Zahoor } \\
\text { et al., 2019) }\end{array}$ & $\begin{array}{l}\mathrm{HC}, \mathrm{CO}, \mathrm{CO}_{2}, \mathrm{NO}_{x}, \mathrm{LNG}, \\
\text { buses, speed, acceleration, } \\
\text { passenger load, and road grade. }\end{array}$ & N/A \\
\hline $\begin{array}{l}\text { (Mohebbi et } \\
\text { al., 2019) }\end{array}$ & $\begin{array}{l}C O, \text { rainfall, temperature, } \\
\text { wind direction, moisture, } \\
\text { and wind speed. }\end{array}$ & $\begin{array}{l}\text { Four } \\
\text { years } \\
(2005- \\
2008)\end{array}$ \\
\hline $\begin{array}{l}\text { (Goulier et } \\
\text { al., 2020) }\end{array}$ & $\begin{array}{l}\mathrm{NO}, \mathrm{NO}_{2}, \mathrm{O}_{3}, \mathrm{NO}_{x}, \mathrm{CO}_{2}, \\
\mathrm{PN}_{10}, \mathrm{NH}_{3}, \mathrm{PM}_{10}, \mathrm{PM}_{2.5} \text {, } \\
\mathrm{PM}_{1}, \text { sound, traffic, time, } \\
\text { temperature, wind direction } \\
\text { and speed, and relative } \\
\text { humidity. }\end{array}$ & $\begin{array}{l}\text { Three } \\
\text { Month } \\
(2018)\end{array}$ \\
\hline $\begin{array}{l}\text { (Azeez et } \\
\text { al., 2019) }\end{array}$ & $\begin{array}{l}C O, \text { heavy truck, buses, } \\
\text { medium truck, and special } \\
\text { duty-truck) cars (taxi and } \\
\text { private cars) and motorbikes, } \\
\text { wind direction, temperature, } \\
\text { and wind speed. }\end{array}$ & $\begin{array}{l}\text { One } \\
\text { Month } \\
\text { (April } \\
\text { 2017) }\end{array}$ \\
\hline $\begin{array}{l}\text { (Xu et } \\
\text { al., 2019) }\end{array}$ & $\begin{array}{l}\mathrm{NO}_{x}, \mathrm{CO}, \mathrm{CO}_{2}, \mathrm{HC}, \\
\text { temperature, humidity, } \\
\text { weather, pressure, wind } \\
\text { speed, and road network. }\end{array}$ & $\begin{array}{l}\text { Three } \\
\text { Month } \\
(2017)\end{array}$ \\
\hline $\begin{array}{l}\text { (Xu et } \\
\text { al., 2017) }\end{array}$ & $\begin{array}{l}\mathrm{CO}, \mathrm{HC}, \mathrm{NO} \text {, traffic } \\
\text { volume, vehicle speed } \\
\text { and length, vehicle } \\
\text { registration, wind speed, } \\
\text { opacity, temperature, } \\
\text { wind direction, pressure, } \\
\text { and humidity. }\end{array}$ & N/A \\
\hline
\end{tabular}

\section{Methodology}

\section{A. Data and Location}

In this paper, air quality, meteorological, and traffic datasets were used. The traffic data was obtained from the Ministry of Works, Malaysia, while the air pollution and meteorological datasets are collected from the Department of Environment (DOE), Malaysia. These datasets are set of observations recorded at a specific time for sixteen hours daily for three years (2014-2016). The $\mathrm{CO}, \mathrm{NO}, \mathrm{NO}_{2}$, and $\mathrm{NO}_{x}$ features from air quality and meteorological features such as relative humidity, wind speed, and temperature were used [36]. The traffic dataset consists of traffic volume, the volume of the type of vehicle (taxi and car, bus, van, heavy and light lorries, and motorcycle), time spent on the road, and speed of the vehicle were used [49]. The traffic dataset was collected from the Ministry of Works Malaysia at Jalan Kepong traffic census station located in Kuala Lumpur, Malaysia.
TABLE II. Summary of the Model's Performance of the Previous STUdies

\begin{tabular}{|c|c|c|c|c|}
\hline Author & Pollutant & MAE & MSE & RMSE \\
\hline $\begin{array}{l}\text { (Wang et } \\
\text { al., 2020) }\end{array}$ & $C O$ & 0.056 & - & 0.088 \\
\hline $\begin{array}{l}\text { (Khan et } \\
\text { al., 2019) }\end{array}$ & $C O$ & 0.347 & - & 0.442 \\
\hline $\begin{array}{l}\text { (Zahoor et } \\
\text { al., 2019) }\end{array}$ & $\begin{array}{l}\mathrm{CO}, \\
\mathrm{CO}_{2}, \\
\mathrm{NO}_{x} \\
\mathrm{HC}\end{array}$ & - & $\begin{array}{l}2.23 \\
52 \\
9.4 \\
0.68 \\
\end{array}$ & - \\
\hline $\begin{array}{l}\text { (Azeez et } \\
\text { al., 2019) }\end{array}$ & $C O$ & - & - & 0.43 \\
\hline $\begin{array}{l}\text { (Goulier } \\
\text { et al., 2020) }\end{array}$ & $\begin{array}{l}\mathrm{NO}, \\
\mathrm{NO}_{2}, \\
\mathrm{O}_{3}, \\
\mathrm{NO}_{x}, \\
\mathrm{CO}_{2}, \\
\mathrm{PN}_{10}, \\
\mathrm{NH}_{3}, \\
\mathrm{PM}_{10}, \\
P M_{2.5}, \\
P M_{1}\end{array}$ & - & - & $\begin{array}{l}16.017 \\
5.092 \\
5.774 \\
32.820 \\
0.790 \\
12,872.27 \\
13.474 \\
0.050 \\
0.013 \\
0.010 \\
\end{array}$ \\
\hline $\begin{array}{l}\text { (Mohebbi et } \\
\text { al., 2019) }\end{array}$ & $C O$ & 0.8925 & - & 1.2736 \\
\hline $\begin{array}{l}\text { (Xu et } \\
\text { al., 2019) }\end{array}$ & $\begin{array}{l}\mathrm{CO}, \\
\mathrm{CO}_{2}, \\
\mathrm{NO}_{x}, \\
\mathrm{HC}\end{array}$ & - & - & $\begin{array}{l}0.0930 \\
0.080 \\
0.0856 \\
0.0798 \\
\end{array}$ \\
\hline $\begin{array}{l}\text { (Xu et } \\
\text { al., 2017) }\end{array}$ & $\begin{array}{l}\mathrm{NO}, \\
\mathrm{CO}, \\
\mathrm{HC}\end{array}$ & - & - & $\begin{array}{l}1.89 \\
0.97 \\
1.09 \\
\end{array}$ \\
\hline
\end{tabular}

\section{B. Design and Development of OANN Model}

An optimized artificial neural network (OANN) was designed and developed to enhance the existing artificial neural network (ANN) model by updating the initial weights in the network using a Genetic Algorithm (GA). An artificial Neural Network (ANN) is an information processing system develop to imitate the human brain's learning and decision-making from experience and examples [50,51]. The structure of the ANN model consists of input layer, hidden layers, and output layer(s). These layers consist of neurons. These neuron's connection is associated with weight and bias. The neurons have an activation function that determines the neuron's output [52]. The structure of the ANN equation is given below [51]:

$$
y=f\left(\sum_{i=1}^{n} w_{i} v_{i}-b\right)
$$

Where $y$ is the output of the network, $n$ is the number of neurons in hidden layers, $w_{i}$ is the weights of the respective neurons, $v_{i}$ is the input values of the neurons, $f$ is the activation function, and $b$ is the bias. The learning process of ANN improves the model's performance during training by updating the weights in the network. The weights of neurons in ANN define how much influence the input has on the output. The initial weights are randomly chosen [53]. The optimization method has been used to improve and update the weights to efficiently improve the model's accuracy.

Optimization is a process of making something better or finding the best solution, or making a good decision. In this study, a Genetic Algorithm (GA) was designed and developed to optimize the initial weights of ANN to improve its performance in this study. GA works as a process of making changes or finding optimal solutions for the problems. GA works on a 
population with a chromosome, and each chromosome has a number of values known as genes [54, 55, 56].

Population in GA represents the entire network's weights (that is, the weights of the input layer to the hidden layer and the weights of the hidden layers to the output layer). Chromosomes represent the weights in one layer (for example, the weights of the input layer to the hidden layer). Finally, Gene represents each neuron's weight (for example, if we have five neurons in the input layer). Fig. 1 illustrates the representations of the GA in the ANN model.

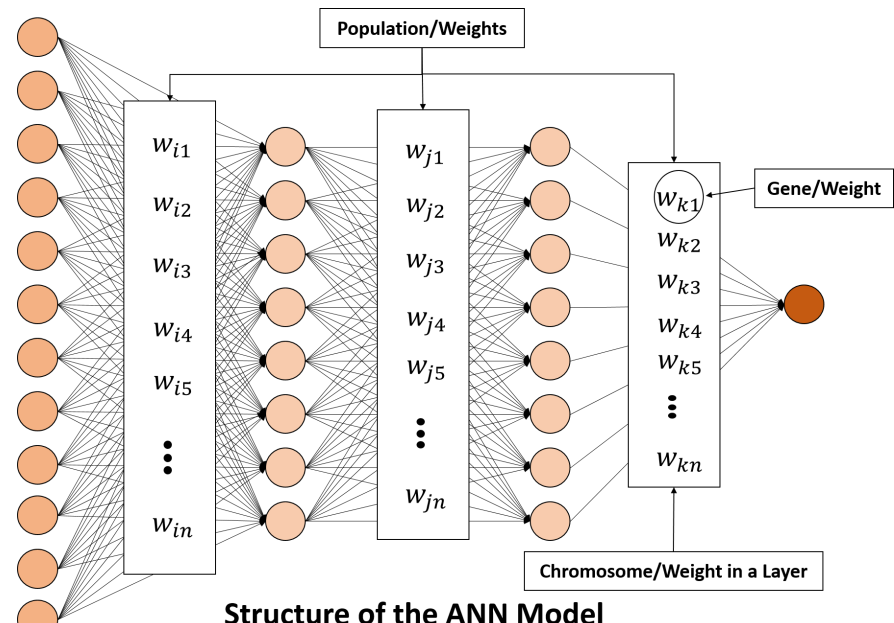

Structure of the ANN Model

Fig. 1. Representation of GA in an ANN Model.

We will create three vectors. The first vector holds the number of chromosomes per population, the second vector holds the size of the population, and the last vector holds the initial population. There are few processes to generate a new and better population. The processes are given below:

1) Select the best parent based on their fitness function.

2) The selected parents will be used to produce offspring.

3) The production of offspring was performed using crossover and mutation.

4) Generated offspring (we create a vector to hold the generated offspring (new population)).

5) The algorithm generates new populations (based on how many generations needed).

6) One of the best population will be selected.

7) The algorithm stops when the optimal solution is found.

Ring pattern was used for selecting parent; for example, if we have ten chromosomes and each chromosome has six genes, the newly generated population will have the same number of chromosomes and genes. If seven chromosomes were found to have the highest fitness value, they would be selected. The remaining three chromosomes will be produced using the ring style. The algorithm will combine the seventh and the first chromosome to produce the eighth one. The first and second chromosomes will be combined to produce the ninth one; we apply a similar way until we get similar chromosomes in the new generation. An example of initial weight (population) is given in Fig. 2.

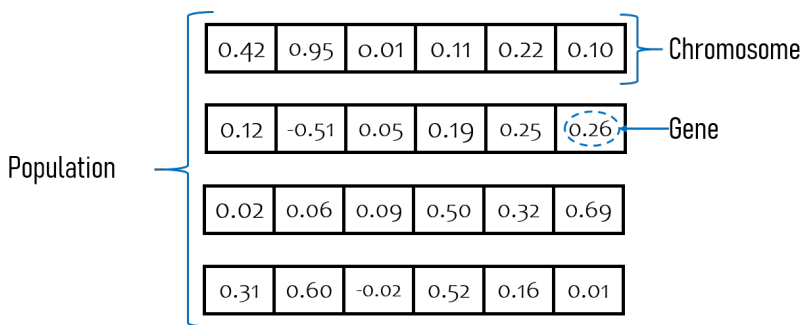

Fig. 2. Population in Genetic Algorithm (GA)/Weights in ANN.

The selection of parents was done by calculating the fitness value or function. This was performed using the equation below $[57,58]$ :

$$
f(c)=2 c+2
$$

Where $f$ is the fitness and $c$ is the chromosome values (genes/weights). An example of a population given in Fig. 2 was calculated in Table III. Based on the table, the first, third, and last chromosomes have the highest fitness values. These parents will be selected to produce new offspring.

TABle III. Fitness VAlues Calculation

\begin{tabular}{|l|l|l|}
\hline Chromosome & Fitness Function & $\begin{array}{l}\text { Parent } \\
\text { Selection }\end{array}$ \\
\hline $\begin{array}{l}0.42+0.95+0.01+0.11+ \\
0.22+0.10=1.61\end{array}$ & $\mathrm{f}(1.72)=2(1.72)+2=5.44$ & 5.44 \\
\hline $\begin{array}{l}0.12+-0.51+0.05+0.19+ \\
0.25+0.26=0.36\end{array}$ & $\mathrm{f}(0.36)=2(0.36)+2=2.72$ & 2.72 \\
\hline $\begin{array}{l}0.02+0.06+0.09+0.50+ \\
0.32+0.69=1.68\end{array}$ & $\mathrm{f}(1.68)=2(1.68)+2=5.36$ & 5.36 \\
\hline $\begin{array}{l}0.31+0.60+-0.02+0.52+ \\
0.16+0.01=1.58\end{array}$ & $\mathrm{f}(1.58)=2(1.58)+2=5.16$ & 5.16 \\
\hline
\end{tabular}

As we have discussed earlier, producing offspring was done through crossover and mutation. The crossover is the process of combining two selected parents to produce two offspring $[56,59]$. The first half of the first parent and last half of the second parent are selected as the first half of the offspring, while the last half of the first parent and the first half of the second parent were chosen as the second half of the offspring. Fig. 3 shows the producing offspring using the crossover.

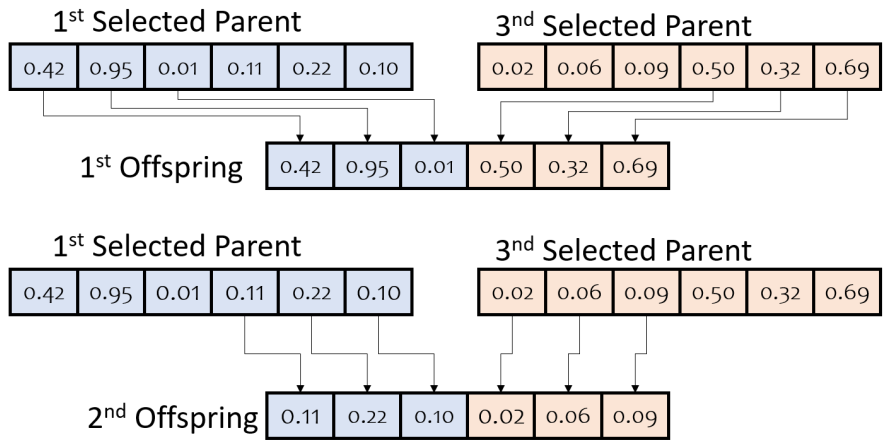

Fig. 3. Producing Offspring Using Crossover. 
The mutation was achieved by changing the gene's (weight) value from the new offspring [57,60]; the altered gene was called a mutant. The gene alteration was done randomly by changing the gene with a lower or higher number than the value of the previous gene range between -1 to 1 . An example of mutation is presented in Fig. 4.

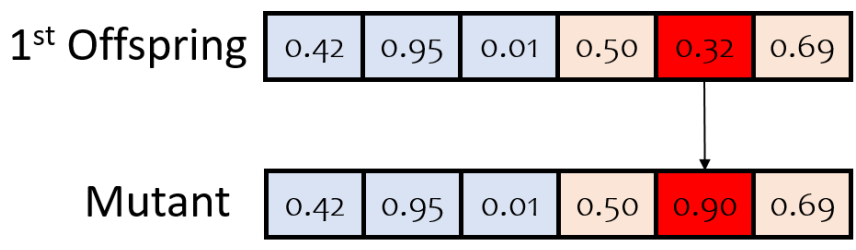

Fig. 4. Producing Offspring Using Mutation.

After the new population was generated, the algorithm produces new generations (based on how many generations are needed). One of the best generations (optimized weights) will be selected and used as the weights of the ANN model. The flow chart of the Genetic Algorithm (GA) for selecting or producing a new solution has been presented in Fig. 5.

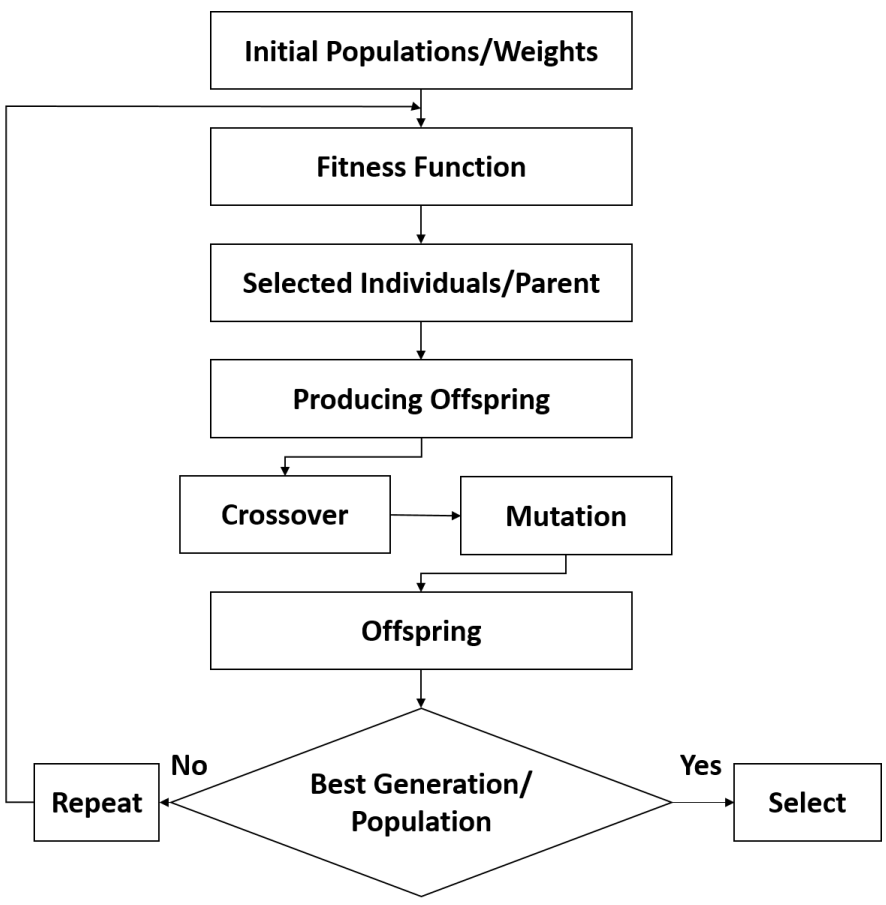

Fig. 5. The Flow Chart of GA for Finding Optimal Solution.

\section{Implementation of the OANN Model}

The developed OANN predictive model was implemented to predict the concentrations of pollutants produced by motor vehicles. The estimated hourly traffic volume, generated vehicle speed and time spent on the road, standardized pollutants values, meteorological and air quality variables were used to train and to test the developed predictive model for traffic emissions concentrations.

The developed OANN model consists of four layers: one input layer, two hidden layers, and one output layer. The input layer consists of 12 inputs: traffic volume, taxi and car volume, bus volume, van volume, heavy lorries volume, light lorries volume, motorcycle volume, time spent on the road, vehicle speed, and relative humidity, wind speed, and temperature. The first hidden layer has ten neurons. The second hidden layer has 100 neurons. The output layer has only one output. The output is the predicted values of the pollutants. For OANN prediction model was created for all the four pollutants namely, $C O, N O$, $\mathrm{NO}_{2}$, and $\mathrm{NO}_{x}$. The linear activation function was used from the output layer. The ReLU activation functions were used for the hidden layers.

The weights of the model were optimized using a Genetic Algorithm. Fifty populations were generated, and one of the best populations was selected. The structure of the OANN model has been presented in Fig. 6 and applying the GA in the model was presented in the Fig. 7.

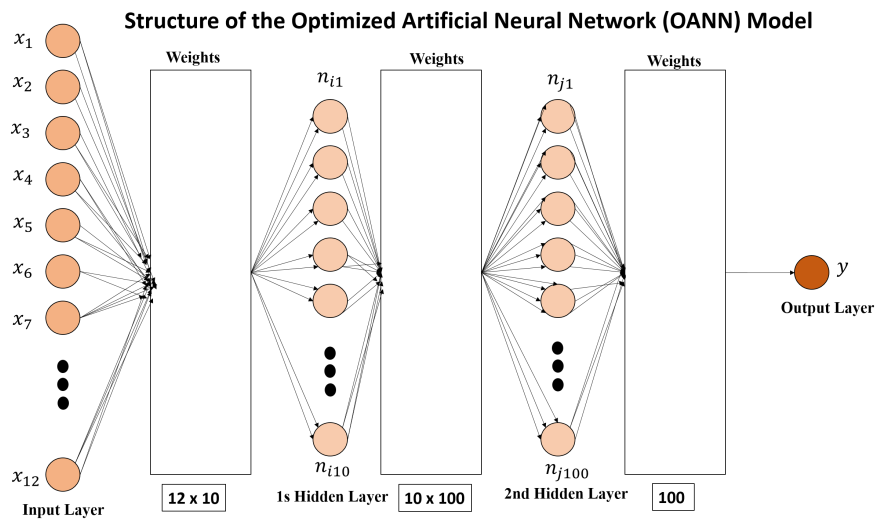

Fig. 6. Structure of the OANN Model.

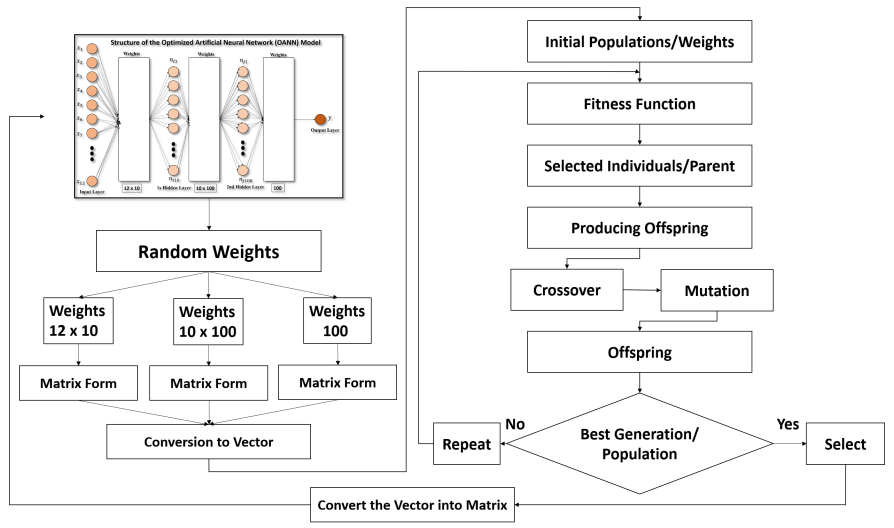

Fig. 7. GA in an OANN Model.

\section{RESUlt AND Discussion}

The developed Optimized Artificial Neural Network (OANN) model was evaluated using two main regression metrics, namely, Mean Absolute Error (MAE), Mean Squared Error (MSE), and comparison with Artificial Neural Network (ANN), Decision Tree (DT), and Random Forest (RF) models. MSE is the difference between the actual and predicted values. The MEA calculates and finds the differences between the 
measure or predicted value and the observed value. Equation 3 used in this study is given below [61]. MSE is the difference between the actual and predicted values. MSE was calculated using equation four [62].

The $n$ is the number of prediction values, $\sum$ represent the summation (adding all the values), $\hat{x}_{i}$ is the predicted values, $x_{i}$ represents the actual values, and $\left|\hat{x}_{i}-x_{i}\right|$ is the absolute errors.

$$
\begin{aligned}
& M A E=\frac{1}{n} \sum_{i=1}^{n}\left|x_{i}-\hat{x}_{i}\right| \\
& M S E=\frac{1}{n} \sum_{i=1}^{n}(x-\hat{x})^{2}
\end{aligned}
$$

An Optimized Artificial Neural Network (OANN) was developed to predict the concentration of traffic emission in Jalan Kepong area, Kuala Lumpur. The OANN was enhanced by updating the initial weights of the ANN model using GA to improve the accuracy of the existing ANN model. There is a total of 1120 initial weights generated by the model. These weights were from the input layer neurons, first hidden layer neurons, and second hidden layer neurons. There are 12 neurons in the input layer, and they are connected to the first hidden layer. There are ten neurons in the first hidden layer, and they are connected to the second hidden layer. Finally, there are 100 neurons in the second hidden layer, and they are attached to the neuron in the output layer. The generated weights were optimized to improve the ANN model. The GA generated 50 populations/optimized weights, and one of the best populations was selected. Fig. 8 presents the best solution or best population/optimized weights for predicting the concentrations of $\mathrm{CO}, \mathrm{NO}, \mathrm{NO}_{2}$, and $\mathrm{NO}_{x}$ emissions.
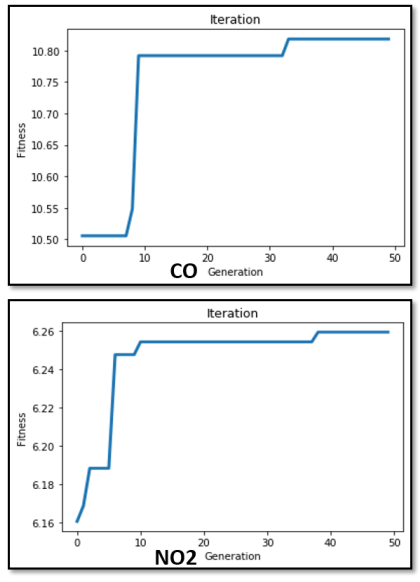

Fig. 8. Best Solution/Population/Weights for Predicting the $\mathrm{CO}, \mathrm{NO}, \mathrm{NO}_{2}$, and $N O_{x}$ Pollutants.

The best set of weights will be selected from the generated 50 population. In Fig. 8 the set of weights was selected after 33 generation for predicting the $C O$ pollutant.

The best set of weights for predicting $N O$ pollutant was selected after 24 generations. Best optimized weights were selected after 38 generations for $\mathrm{NO}_{2}$ prediction. The best set of weights was selected after 45 generations for predicting the level of $N O_{x}$ emissions. Sample of the optimized populations/weights was illustrated in Fig. 9.

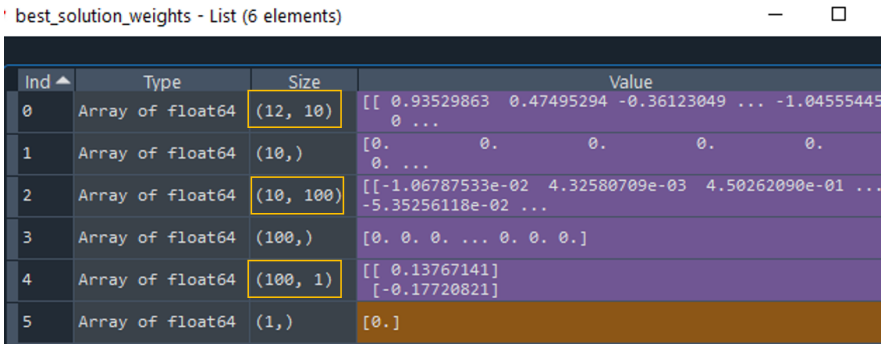

Fig. 9. The Optimized Weights in The Layers.

The highlighted in yellow colors in Fig. 9 were the optimized weights from the input layer to the first hidden layer, which consist of 12 neurons connected to the first hidden layer with ten neurons. The first hidden layer consists of 10 neurons connected to the second hidden layer with 100 neurons. The second or last hidden layer has 100 neurons connected to the output layer with one neuron. The population with the optimized weights were chosen for prediction of the $C O, N O$, $\mathrm{NO}_{2}$, and $\mathrm{NO}_{x}$. The set of the optimized weights for the prediction of the $C O$ pollutant was presented in Fig. 10.
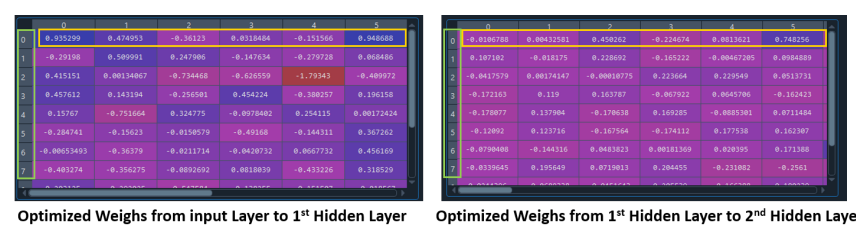

Optimized Weighs from input Layer to $1^{\text {st }}$ Hidden Layer

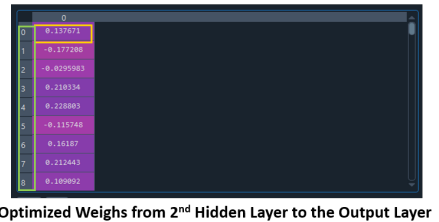

Fig. 10. The Optimized Weights in the Network.

The highlighted green color in Fig. 10 were the number of neurons in the layer. While the highlighted in yellow colors were the number of neurons connected to the next layer.

A sample of the total fitness of each generation by GA for predicting $C O$ pollutant has been given. The fitness values of the first set of weights were 10.505416290436793. There are no changes in the fitness values until the seventh generation. In the eighth generation, there is a change from 10.505416290436793 to 10.548116345442276 . In the ninth generation, there is a change from 10.548116345442276 to 10.791954330972974. From the tenth generation until the thirty-second generation, there were no changes for the fitness functions. In the thirty-three generation, there is a change from 10.791954330972974 to 10.818411975096184 . From thirtyfourth generation until fifty generations there is no change in the fitness value. The highest fitness value of the weights was found in the thirty-three generation. 
The developed Optimized Artificial Neural Network model was used to predict the concentrations of $\mathrm{CO}, \mathrm{NO}, \mathrm{NO}_{2}$, and $N O_{x}$ pollutants emitted by motor vehicles in Jalan Kepong, Kuala Lumpur. Mean absolute error (MAE) and mean squared error (MSE) regression metrics were used to evaluate the performance of the model. Fig. 11 shows the predicted and original values of the pollutants. The prediction of the $C O$ pollutant shows that the model was able to follow the trend of the original values. Similarly, the prediction of $N O$ also follows the trend of the original values with a slightly difference. The OANN model also followed the trends of the original values for predicting the $\mathrm{NO}_{2}$ and $\mathrm{NO}_{x}$ pollutants.
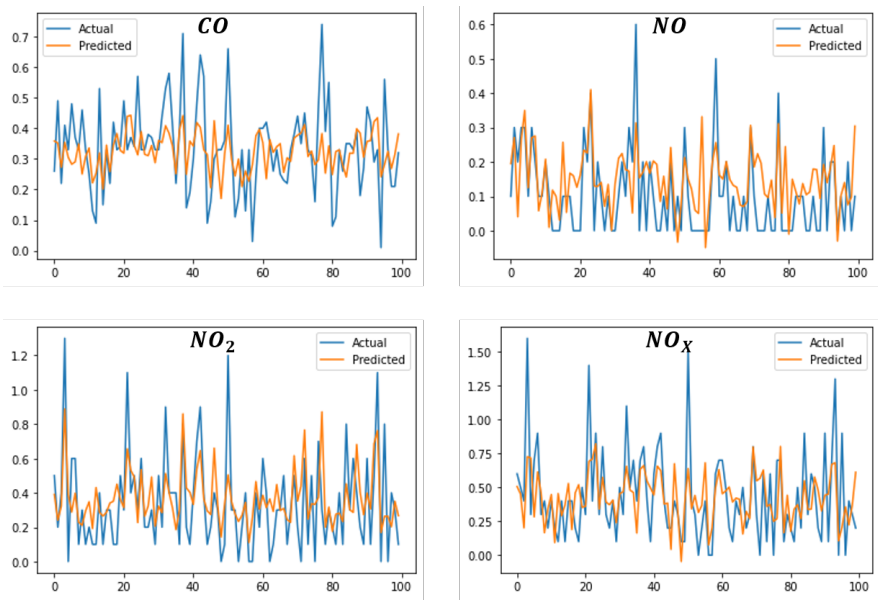

Fig. 11. Predicted Values and the Original Values of the Pollutants Using OANN Model.

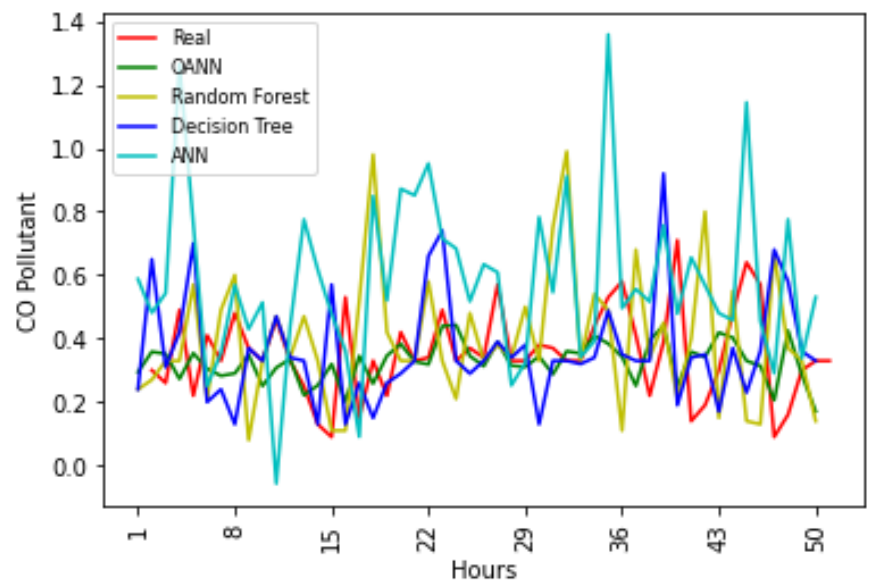

Fig. 12. Comparison of Original values and Predicted Values between OANN, ANN, RF, and DT Models for $C O$ Prediction.

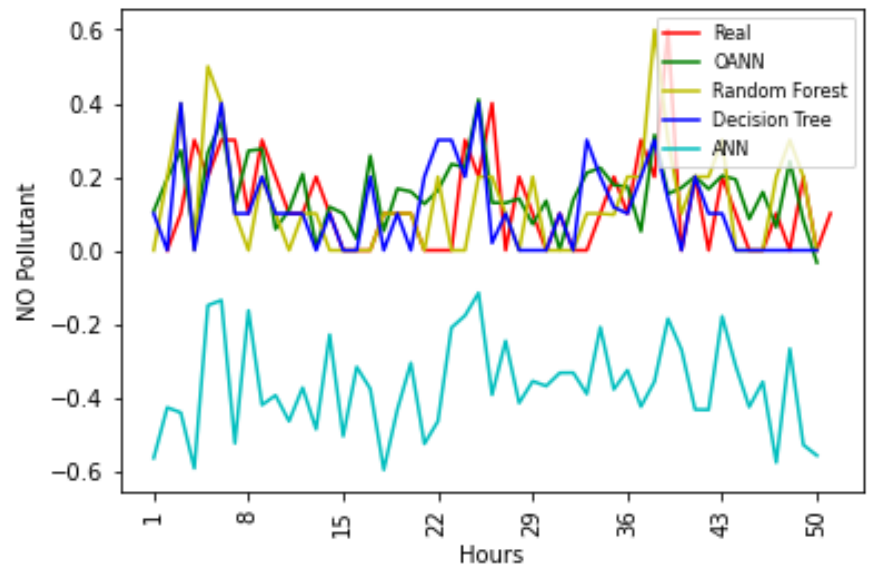

Fig. 13. Comparison of Original values and Predicted Values between OANN, ANN, RF, and DT Models for NO Prediction.

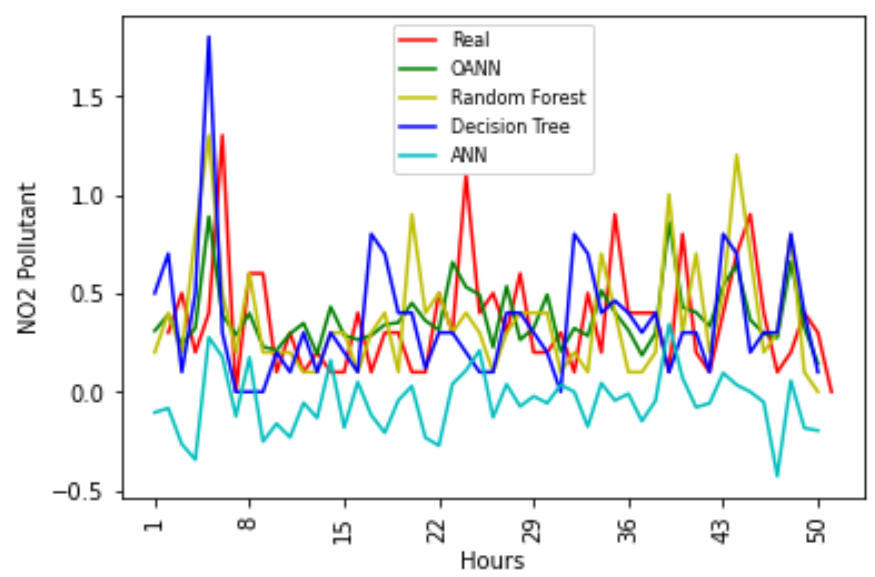

Fig. 14. Comparison of Original values and Predicted Values between OANN, ANN, RF, and DT Models for $\mathrm{NO}_{2}$ Prediction. 


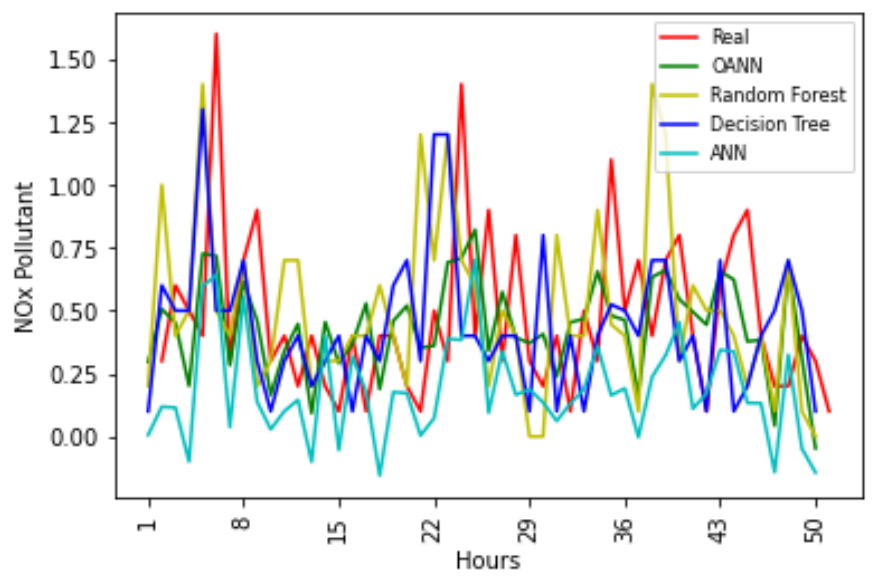

Fig. 15. Comparison of Original values and Predicted Values between OANN, ANN, RF, and DT Models for $N O_{x}$ Prediction.

Table IV presents the comparison of MAE and MSE values between OANN, ANN, RF, and DT for predicting the concentrations of $\mathrm{CO}, \mathrm{NO}, \mathrm{NO}_{2}$, and $\mathrm{NO}_{x}$ pollutants. The result shows the performance of the OANN model for predicting the concentrations of $C O$ was found better than the ANN, DT, and RF models with lowest MAE and MSE values of 0.1155 and 0.0248 . The ANN model performed better than $\mathrm{RF}$ and DT with the lower MSE values of 0.0441 for the $C O$ prediction. The DT model performed a little better than the RF model with lower MAE and MSE scores of 0.1522 and 0.0446 , whilst the MSE and MAE values of RF were 0.0463 and 0.1551 .

The comparison of the OANN, ANN, DT, and RF models shows the significant difference of results in terms of MSE and MAE values for predicting the level of $N O$ pollutant. The MAE and MSE values of the developed model were found lowest compared to DT, RF, and ANN models. The MAE and MSE values were 0.1263 and 0.0365 , and this shows that the enhanced OANN model was better than the RF, ANN, and DT models. The DT model performed better than the RF and ANN models with lower MAE and MSE scores of 0.1446 and 0.0642. The MAE and MSE values of the ANN model were higher than the RF model, which shows that the RF model was performed better than the ANN model. The MAE and MSE values of the RF model were 0.1450, 0.0644, and for the ANN model were 0.5042 and 0.3040 .

The performance of the OANN model is better than the DT, RF, and ANN models with the lowest MAE and MSE values for predicting the concentrations of $\mathrm{NO}_{2}$ emissions. The MAE and MSE values were 0.1731 and 0.0542. Moreover, the performance of the ANN model was found unsatisfactory with the highest MAE and MSE values of $0.3928,0.2288$ more than RF and DT models for the $\mathrm{NO}_{2}$ prediction. The RF model performed better than the DT model for predicting the level of $\mathrm{NO}_{2}$ emissions with a lower MSE value of 0.0810 .

Table IV indicates that the OANN model has the lowest MAE and MSE values than the ANN, DT, and RF models for the prediction of $N O_{x}$ pollutant., this shows that the OANN model performed better than ANN, DT, and RF models. The MAE and MSE scores of the OANN model were 0.2368 and
0.1128. Unfortunately, the DT model has the highest MAE and MSE scores than the ANN and RF models. The MAE and MSE values of the DT model were 0.3178 and 0.2003. However, the RF model performed better than the ANN model with the MAE and MSE values of 0.2872 and 0.1757 for predicting the concentrations of $N O_{x}$ pollutant. The MAE and MSE values of the ANN model were 0.2928 and 0.1812.

TABLE IV. COMPARISON BETWEEN OANN, ANN, DT, AND RF FOR TRAFFIC EMISSIONS PREDICTION

\begin{tabular}{|l|c|c|c|c|c|c|c|c|}
\hline \multirow{2}{*}{ AP } & \multicolumn{2}{|c|}{ OANN } & \multicolumn{2}{c|}{ ANN } & \multicolumn{2}{c|}{ Random Forest } & \multicolumn{2}{c|}{ Decision Tree } \\
\cline { 2 - 9 } & MAE & MSE & MAE & MSE & MAE & MSE & MAE & MSE \\
\hline $\mathrm{CO}$ & $\mathbf{0 . 1 1 5 5}$ & $\mathbf{0 . 0 2 4 7}$ & 0.1696 & 0.0441 & 0.1551 & 0.0463 & 0.1522 & 0.0446 \\
\hline $\mathrm{NO}$ & $\mathbf{0 . 1 2 6 3}$ & $\mathbf{0 . 0 3 6 5}$ & 0.5042 & 0.3040 & 0.145 & 0.0644 & 0.1446 & 0.0642 \\
\hline $\mathrm{NO}_{2}$ & $\mathbf{0 . 1 7 3 1}$ & $\mathbf{0 . 0 5 4 2}$ & 0.3928 & 0.2288 & 0.2024 & 0.0810 & 0.2007 & 0.0826 \\
\hline $\mathrm{NO}_{x}$ & $\mathbf{0 . 2 3 6 8}$ & $\mathbf{0 . 1 1 2 8}$ & 0.2928 & 0.1812 & 0.2872 & 0.1757 & 0.3178 & 0.2003 \\
\hline
\end{tabular}

It can be concluded that the developed OANN model achieved the best results in comparison with all models, especially the ANN model for predicting the concentrations of $\mathrm{CO}, \mathrm{NO}, \mathrm{NO}_{2}$, and $\mathrm{NO}_{x}$ pollutants.

\section{CONCLUSiON}

A based Artificial Neural Network (OANN) model was developed to enhance the existing ANN model by updating the initial weights that connect the neurons in the network using a Genetic Algorithm (GA). The OANN model was used to predict the level of pollutants emitted by vehicles in Kuala Lumpur, Malaysia. The OANN model was evaluated using performance metrics and comparison with ANN, DT, and RF models. The result shows the developed OANN model performed better than the existing ANN, DT, and RF models with the lowest regression metrics when compared.

Based on the literature review, the study of [45] predicts the concentration of air pollutants at canyon street. Still, our study predicts the level of air pollutants at the roadside, which is an open space. [46] study was the closest study with our study; the difference is, the study focuses more on the truck vehicles and also used a one-month dataset. Additionally, they predict the concentrations of $C O$ pollutants. Our study added three more pollutants namely, $\mathrm{NO}, \mathrm{NO}_{2}$, and $\mathrm{NO}_{x}$. The study of [48] used different variables such as length of the vehicle, vehicle registration, and opacity. The study also has a higher RMSE score than the RMSE values of our study.

The developed OANN model can help environmental agencies monitor traffic-related air pollution levels efficiently and take necessary actions to ensure the effectiveness of traffic management policy. Moreover, the model can help decisionmakers mitigate traffic emissions to protect the health of the citizens who are inhabiting very close to highways.

Admittedly, there are some limitations to this study. Firstly, Some studies suggested that different types of fuel have different types of emissions, but the fuel type was not considered in this study. The Jalan Kepong traffic census station was selected, but the other stations were not considered. There are many pollutants emitted by motor vehicles. However, the developed OANN model was limited to predict the hourly $C O$, $\mathrm{NO}, \mathrm{NO}_{2}$, and $\mathrm{NO}_{x}$ concentrations. It can be applied to the other traffic pollutants as well. Furthermore, daily, weekly, 
monthly, or yearly predictions were not the focus of this research. The prediction using only one type of vehicle was not considered as well.

\section{ACKNOWLEDGMENT}

This research is funded by Taylor's University under the research grant application ID (TUFR/2017/004/04) entitled as "Modeling and Visualization of Air-Pollution and its Impacts on Health".

\section{REFERENCES}

[1] M. Bilal, R. S. A. Usmani, M. Tayyab, A. A. Mahmoud, R. M. Abdalla, M. Marjani, T. R. Pillai, and I. A. Targio Hashem, "Smart cities data: Framework, applications, and challenges," Handbook of Smart Cities, pp. 1-29, 2020.

[2] R. S. A. Usmani, I. A. T. Hashem, T. R. Pillai, A. Saeed, and A. M Abdullahi, "Geographic information system and big spatial data: A review and challenges," International Journal of Enterprise Information Systems (IJEIS), vol. 16, no. 4, pp. 101-145, 2020.

[3] Z. Sun, C. Wang, Z. Ye, and H. Bi, "Long short-term memory networkbased emission models for conventional and new energy buses," International Journal of Sustainable Transportation, vol. 15, no. 3, pp. 229-238, 2021.

[4] C.-H. Lai, P.-K. Hsiao, Y.-T. Yang, S.-M. Lin, and S.-C. C. Lung, "Effects of the manual and electronic toll collection systems on the particulate pollutant levels on highways in taiwan," Atmospheric Pollution Research, vol. 12, no. 3, pp. 25-32, 2021.

[5] L. Bertrand, L. Dawkins, R. Jayaratne, and L. Morawska, "How to choose healthier urban biking routes: Co as a proxy of traffic pollution," Heliyon, vol. 6, no. 6, p. e04195, 2020.

[6] R. S. A. Usmani, T. R. Pillai, I. A. T. Hashem, N. Z. Jhanjhi, A. Saeed, and A. M. Abdullahi, "A spatial feature engineering algorithm for creating air pollution health datasets," International Journal of Cognitive Computing in Engineering, vol. 1, pp. 98-107, 2020.

[7] J. Huang, G. Song, J. Zhang, C. Li, Q. Liu, and L. Yu, "The impact of violations of bicycles and pedestrians on vehicle emissions at signalized intersections," Journal of advanced transportation, vol. 2020, 2020.

[8] J. Su, "Portable and sensitive air pollution monitoring," Light, science \& applications, vol. 7, 2018.

[9] R. S. A. Usmani, T. R. Pillai, I. A. T. Hashem, M. Marjani, R. Shaharudin, and M. T. Latif, "Air pollution and cardiorespiratory hospitalization, predictive modeling, and analysis using artificial intelligence techniques," Environmental Science and Pollution Research, pp. 1-13, 2021.

[10] S. Munir, M. Mayfield, and D. Coca, "Understanding spatial variability of no2 in urban areas using spatial modelling and data fusion approaches," Atmosphere, vol. 12, no. 2, p. 179, 2021.

[11] R. S. A. Usmani, A. Saeed, A. M. Abdullahi, T. R. Pillai, N. Z. Jhanjhi, and I. A. T. Hashem, "Air pollution and its health impacts in malaysia: a review," Air Quality, Atmosphere \& Health, vol. 13, no. 9, pp. 1093 $1118,2020$.

[12] S. Kim, C. Xiao, I. Platt, Z. Zafari, M. Bellanger, and P. Muennig, "Health and economic consequences of applying the united states' pm2. 5 automobile emission standards to other nations: a case study of france and italy," Public health, vol. 183, pp. 81-87, 2020.

[13] Y. Romero, C. Diaz, I. Meldrum, R. A. Velasquez, and J. Noel, "Temporal and spatial analysis of traffic-related pollutant under the influence of the seasonality and meteorological variables over an urban city in peru," Heliyon, vol. 6, no. 6, p. e04029, 2020.

[14] J. Zheng, S. Dong, Y. Hu, and Y. Li, "Comparative analysis of the co2 emissions of expressway and arterial road traffic: A case in beijing," PloS one, vol. 15, no. 4, p. e0231536, 2020.

[15] X. Bing, Q. Wei, J. Lu, C. Li, and Y. Zhang, "Sustainable highway design: Disentangling the effects of geometric-related and traffic-related factors on urban highway traffic emissions," Advances in Civil Engineering, vol. 2018, 2018.

[16] A. Sfyridis and P. Agnolucci, "Road emissions in london: Insights from geographically detailed classification and regression modelling," Atmosphere, vol. 12, no. 2, p. 188, 2021

[17] R. Akhtar and C. Palagiano, "Climate change and air pollution," Switzerland: Springer International Publishing, AG, 2018.
[18] X. Shi, D. J. Sun, Y. Zhang, J. Xiong, and Z. Zhao, "Modeling emission flow pattern of a single cruising vehicle on urban streets with cfd simulation and wind tunnel validation," International Journal of Environmental Research and Public Health, vol. 17, no. 12, p. 4557, 2020.

[19] D. Pan, L. Tao, K. Sun, L. M. Golston, D. J. Miller, T. Zhu, Y. Qin, Y. Zhang, D. L. Mauzerall, and M. A. Zondlo, "Methane emissions from natural gas vehicles in china," Nature communications, vol. 11, no. 1, pp. 1-10, 2020.

[20] N. Abdull, M. Yoneda, and Y. Shimada, "Traffic characteristics and pollutant emission from road transport in urban area," Air Quality, Atmosphere \& Health, vol. 13, no. 6, pp. 731-738, 2020.

[21] M. Masoudi, N. Rajaipoor, and F. Ordibeheshti, "Status of pm10 as an air pollutant and prediction using meteorological indexes in shiraz, iran," Advances in environmental research, vol. 7, no. 2, pp. 109-120, 2018.

[22] M. Kermani, A. J. Jafari, M. Gholami, F. Fanaei, H. Arfaeinia et al., "Association between meteorological parameter and pm2. 5 concentration in karaj, iran," International Journal of Environmental Health Engineering, vol. 9, no. 1, p. 4, 2020.

[23] H. Zhou, Y. Yu, X. Gu, Y. Wu, M. Wang, H. Yue, J. Gao, R. Lei, and X. Ge, "Characteristics of air pollution and their relationship with meteorological parameters: Northern versus southern cities of china," Atmosphere, vol. 11, no. 3, p. 253, 2020.

[24] H. Cui, R. Ma, and F. Gao, "Relationship between meteorological factors and diffusion of atmospheric pollutants," Chemical Engineering Transactions, vol. 71, pp. 1417-1422, 2018.

[25] M. S. Jamil, A. Z. Ul-Saufie, A. Abu Bakar, K. A. M. Ali, and H. Ahmat, "Identification of source contributions to air pollution in penang using factor analysis," Int J Integr Eng, vol. 11, no. 8, pp. 221-228, 2019.

[26] A. Nazif, N. I. Mohammed, A. Malakahmad, and M. S. Abualqumboz, "Evaluating the influence of meteorological parameters on ozone concentration levels," International Journal of Engineering \& Technology, vol. 7, no. 3.7, pp. 65-67, 2018.

[27] A. A. A. Mohtar, M. T. Latif, N. H. Baharudin, F. Ahamad, J. X. Chung, M. Othman, and L. Juneng, "Variation of major air pollutants in different seasonal conditions in an urban environment in malaysia," Geoscience Letters, vol. 5, no. 1, p. 21, 2018.

[28] R. Rossi, R. Ceccato, and M. Gastaldi, "Effect of road traffic on air pollution. experimental evidence from covid-19 lockdown," Sustainability, vol. 12, no. 21, p. 8984, 2020.

[29] P. Krecl, Y. A. Cipoli, A. C. Targino, L. B. Castro, L. Gidhagen, F. Malucelli, and A. Wolf, "Cyclists' exposure to air pollution under different traffic management strategies," Science of the Total Environment, vol. 723 , p. $138043,2020$.

[30] S. S. Anjum, R. M. Noor, N. Aghamohammadi, I. Ahmedy, L. M. Kiah, N. Hussin, M. H. Anisi, and M. A. Qureshi, "Modeling traffic congestion based on air quality for greener environment: an empirical study," IEEE Access, vol. 7, pp. 57 100-57 119, 2019.

[31] B. Choubin, M. Abdolshahnejad, E. Moradi, X. Querol, A. Mosavi, S. Shamshirband, and P. Ghamisi, "Spatial hazard assessment of the pm10 using machine learning models in barcelona, spain," Science of The Total Environment, vol. 701, p. 134474, 2020.

[32] A. Suleiman, M. Tight, and A. Quinn, "Applying machine learning methods in managing urban concentrations of traffic-related particulate matter (pm10 and pm2. 5)," Atmospheric Pollution Research, vol. 10, no. 1, pp. 134-144, 2019.

[33] I. Šimić, M. Lovrić, R. Godec, M. Kröll, and I. Bešlić, "Applying machine learning methods to better understand, model and estimate mass concentrations of traffic-related pollutants at a typical street canyon," Environmental Pollution, vol. 263, p. 114587, 2020.

[34] V. Gnanamoorthi, P. Purushothaman, A. Gurusamy, G. Devaradjane et al., "Prediction efficiency of artificial neural network for crdi engine output parameters," Transportation Engineering, vol. 3, p. 100041, 2021.

[35] M. Nandal, N. Mor, and H. Sood, "An overview of use of artificial neural network in sustainable transport system," Computational Methods and Data Engineering, pp. 83-91, 2021.

[36] I. A. T. Hashem and T. R. Pillai, "A novel feature engineering algorithm for air quality datasets," Indonesian Journal of Electrical Engineering and Computer Science, vol. 19, no. 3, pp. 1444-1451, 2020.

[37] E. López-Pérez, T. Hermosilla, J.-M. Carot-Sierra, and G. PalauSalvador, "Spatial determination of traffic co emissions within street canyons using inverse modelling," Atmospheric Pollution Research, vol. 10, no. 4, pp. 1140-1147, 2019.

[38] M. Hilpert, M. Johnson, M.-A. Kioumourtzoglou, A. Domingo-Relloso, A. Peters, B. Adria-Mora, D. Hernández, J. Ross, and S. N. Chillrud, 
"A new approach for inferring traffic-related air pollution: Use of radarcalibrated crowd-sourced traffic data," Environment international, vol. 127, pp. 142-159, 2019.

[39] M. Gustafsson, G. Blomqvist, I. Järlskog, J. Lundberg, S. Janhäll, M. Elmgren, C. Johansson, M. Norman, and S. Silvergren, "Road dust load dynamics and influencing factors for six winter seasons in stockholm, sweden," Atmospheric Environment: X, vol. 2, p. 100014, 2019.

[40] C. Xu, J. Zhao, and P. Liu, "A geographically weighted regression approach to investigate the effects of traffic conditions and road characteristics on air pollutant emissions," Journal of Cleaner Production, vol. 239, p. 118084, 2019.

[41] Y. Wang, P. Liu, C. Xu, C. Peng, and J. Wu, "A deep learning approach to real-time co concentration prediction at signalized intersection," Atmospheric Pollution Research, vol. 11, no. 8, pp. 1370-1378, 2020.

[42] M. J. U. R. Khan and A. Awasthi, "Machine learning model development for predicting road transport ghg emissions in canada," WSB Journal of Business and Finance, vol. 53, no. 2, pp. 55-72, 2019.

[43] O. Zahoor, M. Usama, Q. Bao, Z. Abbas, Y. Shen, and S. Chen, "Lng bus emissions prediction using neural network," in CICTP 2019. ASCE, 2019, pp. 4156-4168.

[44] M. R. Mohebbi, A. K. Jashni, M. Dehghani, and K. Hadad, "Shortterm prediction of carbon monoxide concentration using artificial neural network (narx) without traffic data: Case study: Shiraz city," Iranian Journal of Science and Technology, Transactions of Civil Engineering, vol. 43, no. 3, pp. 533-540, 2019.

[45] L. Goulier, B. Paas, L. Ehrnsperger, and O. Klemm, "Modelling of urban air pollutant concentrations with artificial neural networks using novel input variables," International journal of environmental research and public health, vol. 17, no. 6, p. 2025, 2020.

[46] O. S. Azeez, B. Pradhan, H. Z. Shafri, N. Shukla, C.-W. Lee, and H. M. Rizeei, "Modeling of co emissions from traffic vehicles using artificial neural networks," Applied Sciences, vol. 9, no. 2, p. 313, 2019.

[47] Z. Xu, Y. Cao, and Y. Kang, "Deep spatiotemporal residual early-late fusion network for city region vehicle emission pollution prediction," Neurocomputing, vol. 355, pp. 183-199, 2019.

[48] Z. Xu, Y. Kang, and W. Lv, "Analysis and prediction of vehicle exhaust emission using ann," in 2017 36th Chinese Control Conference (CCC). IEEE, 2017, pp. 4029-4033.

[49] A. M. Abdullah, R. S. A. Usmani, T. R. Pillai, I. A. T Hashem, and M. Marjani, "Feature engineering algorithms for traffic dataset," International Journal of Advanced Computer Science and Applications, vol. 12, no. 4, 2021. [Online]. Available: http: //dx.doi.org/10.14569/IJACSA.2021.0120435

[50] B. Liu, Q. Zhao, Y. Jin, J. Shen, and C. Li, "Application of combined model of stepwise regression analysis and artificial neural network in data calibration of miniature air quality detector," Scientific Reports, vol. 11, no. 1, pp. 1-12, 2021.

[51] M. Nandal, N. Mor, and H. Sood, "An overview of use of artificial neural network in sustainable transport system," Computational Methods and Data Engineering, pp. 83-91, 2020.

[52] R. Kenanoğlu, M. K. Baltacioğlu, M. H. Demir, and M. E. Özdemir, "Performance \& emission analysis of hho enriched dual-fuelled diesel engine with artificial neural network prediction approaches," International Journal of Hydrogen Energy, vol. 45, no. 49, pp. 26357-26369, 2020.

[53] R. E. Neapolitan and R. E. Neapolitan, "Neural networks and deep learning," Artificial Intelligence, pp. 389-411, 2018.

[54] S. Mirjalili, "Genetic algorithm," in Evolutionary algorithms and neural networks. Springer, 2019, pp. 43-55.

[55] N. Razmjooy, M. Ashourian, and Z. Foroozandeh, Metaheuristics and Optimization in Computer and Electrical Engineering. Springer, 2019.

[56] G. Zhang, C. Xiao, and N. Razmjooy, "Optimal parameter extraction of pem fuel cells by meta-heuristics," International Journal of Ambient Energy, pp. 1-10, 2020.

[57] A. F. Gad, A. F. Gad, and S. John, Practical computer vision applications using deep learning with CNNs. Springer, 2018.

[58] N. Razmjooy, V. V. Estrela, H. J. Loschi, and W. Fanfan, "A comprehensive survey of new meta-heuristic algorithms," Recent Advances in Hybrid Metaheuristics for Data Clustering, Wiley Publishing, 2019.

[59] N. Razmjooy, V. V. Estrela, and H. J. Loschi, "Entropy-based breast cancer detection in digital mammograms using world cup optimization algorithm," International Journal of Swarm Intelligence Research (IJSIR), vol. 11, no. 3, pp. 1-18, 2020.

[60] N. Razmjooy, M. Khalilpour, and M. Ramezani, "A new meta-heuristic optimization algorithm inspired by fifa world cup competitions: theory and its application in pid designing for avr system," Journal of Control, Automation and Electrical Systems, vol. 27, no. 4, pp. 419-440, 2016.

[61] T. Chai and R. R. Draxler, "Root mean square error (rmse) or mean absolute error (mae)?-arguments against avoiding rmse in the literature," Geoscientific model development, vol. 7, no. 3, pp. 1247-1250, 2014.

[62] Z. Wang and A. C. Bovik, "Mean squared error: Love it or leave it? a new look at signal fidelity measures," IEEE signal processing magazine, vol. 26, no. 1, pp. 98-117, 2009. 